\title{
LA PERDURACION DE UN TOPONIMO DE LA VIA AUGUSTA: LUBRICATUM / RAHAL AL-LOBRECATI / TURRIS DE LUPRICATO
}

\author{
Por \\ ENRIQUE A. LLOBREGAT
}

Esta notita es fruto del azar más peregrino. De una parte el análisis de un topónimo de la calzada romana registrada por el Ravenate de cara a la preparación de un estudio (1); de otra una lectura de A. Poveda en la que aparecían unos gentilicios curiosos por su referencia clara a mi propio apeIlido. En principio nada llevaba a comunicarlos salvo una cierta curiosidad por lo raro que a veces es fructífera. Ella me llevó de la mano de Poveda, a consultar algunos datos más con Guichard que me proporcionó una vía clave para seguir adelante en la encuesta. En fin, una vez elaborada la hipótesis, J. Gil me ayudó mucho con su conocimiento geográfico de las tierras de Castellón y con el aporte de subsidios bibliográficos. Vaya a Pierre Guichard, a Angel Poveda y a Pepe Gil mi agradecimiento por su capital ayuda. La exploración no está conclusa, pero con lo allegado hasta el momento pienso que se puede hacer una primera y apresurada exposición cuyo principal fin es el de despertar en los lectores que posean alguna información el deseo de terciar en el tema con lo que todos saldremos ganando, historiadores de la antigüedad romana hispánica, arabistas y medievalistas así como los afectos a la geografía antigua e incluso a la toponimia.

\section{El trazado de la vía según el Anónimo de Ravena}

Lo he reestudiado recientemente (2) y tan sólo me voy a detener en el análisis de la mansión Rubricatum / Lubricatum. Paralelizable con la Rou-

(1) E.A. LLOBREGAT, Relectura del Ravenate: dos calzadas, una mansión inexistente y otros datos de la geografía antigua del Pais Valenciano, Lucentum, HI, 1983, 225-42. Ibíd. La geografia antiga valenciana i "l'Anónim de Ravenna»: notes de lectura, L'Espill, 17/18, 1983, 99-111.

(2) Vide nota 1. 
brikata de Ptolomeo (II, 6, 72) la toponimia posterior hace fuerza sobre la forma Lubricatum, y aun Laubricatum, como figura en la Geographia de Guido. Precisamente esa forma nos conduce -conociendo el topónimo posterior- a una fuente islámica para Guido y aun para el Ravenate ya que la inicial Lau nos muestra la posibilidad de una lectura latina de un topónimo escrito en caracteres árabes que comenzaría por lam waw, lo que daría pie, en un lector no avezado a transcripciones como $L u$-, $L O$-, o incluso Lau.

Precisamente Lubricatum / Rubricatum es una de las mansiones de la vía romana que por su aparición tardía en los textos plantea fuertes problemas de identificación a los autores, que se inclinan por un topónimo desplazado que aludiría a tierras cercanas al río Llobregat (Roubrikatos potamos) en opinión de Roldán (3) o a una no-identificación apoyada en la alteración del orden de los topónimos de la vía (4) que dice textualmente que es un lugar de «difícil localización».

Efectivamente, la lista de topónimos del Ravenate a partir de Dertosa muestra alteraciones de orden, quizá debidas a incuria de los copistas. pero que son -al parecer- bastante evidentes. Es un factor más que contribuye a la dificultad de la reducción y a la falta de un tracto sucesivo de topónimos que por primera vez se insinúa en esta nota.

\section{Una clave de localización: el Rahal Alubrecati}

En un reciente artículo, Poveda aludía a unos moros que figuran en el "Repartiment» de Mallorca y que procedian de un Rahal Alubrecati (5). A mayor abundamiento señala que rahal hay que entenderlo en el sentido de parada, jornada o descanso, lo que se avenía perfectamente con la posta de la vía romana y la mansio Lubricati quedaba calcada semánticamente por el rahal al-Lubrecati. Señalaba además que este lugar se encontraba en un área comprendida entre Alcalá de Xivert y Burriana.

La comprobación del dato me vino tras un despojo lento de los índices de la edición Ferrando del «Repartiment» de Valencia (6), sensiblemente mejor que las anteriores y contemporáneas que pecaban en el último caso de excesivo aragonesismo. Entre los habitantes de la ciudad encontramos un discreto grupo de gentes que, por su gentilicio, provienen de aquel lugar. Hay un Abdalla Lobrecatí $(1611,3670)$, un Aly Lobrecatí (1526, 1527), un Mahomat Alquinet Lobrecatí (3627) o incluso un simple Lobreccatí (3288).

(3) J. M. ROLDAN, tineraria Hispana, Valladolid, 1975.

(4) J. G. MORoTE, El trazado de la Via Augusta desde Tarracone a Carthagine Spartaria. Saguntum, Papeles del Laboratorio de Arqueología de Valencia, 14, 1979, 139 ss. C $f$. ibíd. el manuscrito de la Memoria de Licenciatura, que he podido consultar por gentileza del autor, en el que se hace la afirmación citada.

(5) A. POVEDA, Toponimia árabe musulmana de Mayûrqa, Awraq, 3, 1980, 98 ss.

(6) Llibre del Repartiment de València, edición dirigida por A. FERRANDO FRANCES, Valencia, R. Vicent, 1979. 
La evidencia no dejaba lugar a dudas y a mi juicio parece lícito -de momento $y$ dentro de la hipótesis-identificar el topónimo tardorromano con el rahal al-Lobrecatí de los repartimientos de Mallorca y Valencia. El emplazamiento geográfico del topónimo quedaba, de todas maneras, en el aire. A tal fin me dirigí a P. Guichard que tenía documentación sobre el topónimo según me comentó Poveda. Con su gentileza acostumbrada respondió a vuelta de correo, indicándome un documento del rey don Jaime en que había una mención relacionable con el lugar que me inquietaba.

Se trata de la donación que hizo el rey al obispado de Tortosa en 27 de abril de 1225 (esto es antes de la conquista) de los castillos de Mirabet y de Zúfera y de sus respectivos territorios (7). Seguidamente copio la parte geográfica del texto del documento que es la que nos interesa en este asunto: «... damus... in perpetuum ad habendum et possidendum duo castra, videlicet castrum Mirabeti et castrum Cufere, quorum affrontaciones taliter terminantur: includunt quidem isti termini omnia et tota montanea de Abinzulus et vadunt alatalaya de Aliub Abenzugaya et de Abenirrabe usque ad turrem de Lupricato et usque ad mare et de mari usque ad Coves et de Coves sicut vadit via maior usque ad Tauranza et vadunt usque ad Almaiexer et de Almaiexer usque ad Penes et de Penis usque ad Rafalvazir et de Rafalvazir usque ad Gaidenes ed de Gaidenes ad Euxer usque ad Zuferam et sic revertuntur ad Mirabetum...».

Hay que destacar, antes de entrar al análisis de los topónimos, la mención de la Vía Maior que nos pone en el ámbito de la calzada romana a mi juicio y al de otros autores mejor conocedores que yo de la geografía castellonense $y$ de su documentación medieval (8).

Con cartografía de diferentes escalas busqué, en vano, alguno de los topónimos presentes en la donación. Todos ellos habían desaparecido con los años y salvo Coves, que evidentemente aludía a Coves de Vinromà, ninguno de los otros era identificable. Estaba además la noticia de Poveda, de hallarse el emplazamiento del rahal lobrecati entre Burriana y Alcalá, lo que aún complicaba más el análisis. Busqué después en la bibliografía, con escasa fortuna. Sin embargo, un estudio de M. Betí (9) daba alguna luz aunque quizá no toda la que hiciera falta. Publicado en 1921, no debe de haber habido muchas aportaciones sobre el tema ya que en época reciente otro artículo de F. Roca Traver reproducía lo esencial del mencionado sin modificación alguna (10).

(7) Documentos de Jaime 1, 1, 66. Edición A. CABANES y A. HUICl, Valencia, Anubar, 1976, 137.

(8) F. ESTEVE GALVEZ, El abrigo rupestre de/ Assud d'Almazora y su vacimienta arqueo/ógico, Archivo de Prehistoria Levantina, XII, 1969, 45: «este último pasó a ser la Vía Augusta... via maior de que hablan documentos medievales".

(9) M. BETI, E/ casti/lo de Mirabet y sus sufragáneos, Boletín de la Sociedad Castellonense de Cultura, II, 1921, 186-87, 300-303.

(10) F. ROCA TRAVER, El origen de un nombre: Torreblanca. La primitiva iglesia de San Francisco. Revista de Fiestas de Torreblanca, s.a. 


\section{Análisis de la donación del rey don Jaime}

Seguiré punto por punto las atribuciones de M. Betí que de entrada explica que el distrito de Mirabet ocupaba el castillo de Albalat, la villa de Cabanes y los lugares de Benlloch y de Torreblanca. Por lo que hace a los topónimos individuales identifica y reduce la montaña de Abinzulus a la parte oriental del desierto de las Palmas, con dudas. Abenibarre lo paraleliza con una Subarra mencionada en las cartas pueblas de Benlloch y de Villanueva.

Por lo que hace a la Turris de Lupricato «creemos que es esta torre la actual Torreblanca». Coves, «se refiere a la frontera del término general de Coves y por tanto la de Villanueva». Almaiexer figura con el nombre de Almediexer que es uno de los límites de la carta puebla de Villanueva. Penes (= peñas a su juicio) lo identifica, con dudas, con la sierra de En Garcerán.

Rafalvazir es un poblado de la Vall d'Alba. Gaidenes sería el monte Gaidó, a poniente de Cabanes. En fin, Euxer sería el valle donde está el santuario de Les Santes, en término de Cabanes. F. Roca añade como novedad que Almaiexer es la partida de Almedíxer, del término de Torreblanca y también se muestra convencido de que la Turris de Lupricato sea la actual Torreblanca.

El área así descrita es relativamente homogénea y podría formàr un conjunto coherente. Se podría enclavar entre las actuales Coves de Vinromá, Alcalá de Xivert, Vilanova d'Alcolea, Vall d'Alba, Cabanes, Orpessa y Albalat. Pero los conflictos y las complicaciones surgen cuando intentamos seguir una delimitación de acuerdo con el orden de las menciones del documento de donación de don Jaume y apoyándonos en las atribuciones de mossén Betí. Desde la montaña de Abinzulus que quedaría a levante de la línea entre Borriol y la Puebla Tornesa va a Benlloch y Villanueva de Alcolea. De aquí a la ignota torre de Lupricat -que no puede ser Torreblanca porque ha de estar sobre la vía romana del interior- y que no tiene aún reducción exacta. De esta torre va al mar, un dato más que no conviene a la reducción de Torreblanca, y desde la mar a Coves (de Vinromà). Desde allí, siguiendo la vía romana (sicut vadit via maior) a Tauranza (?) y Almaiexer, dentro del término municipal de Torreblanca según Roca. El último tramo de esta delimitación sigue por la sierra de En Garcerán, el monte Gaidó y Euxer, ambos en término de Cabanes. Sea por lo hipotético de muchas de las reducciones o porque están claramente erradas las identificaciones, la línea que sobre el mapa se puede trazar siguiendo estos puntos es caótica e informe. Amén de que no ayuda nada en la búsqueda del emplazamiento de la Turris de Lupricato.

\section{Una hipotética identificación}

Mapas en mano y con el trazado de la vía que está bastante bien analizado en sus líneas generales por Morote, que recoge con precisión toda 
la bibliografía anterior (11) aparece un lugar con yacimiento romano y con un topónimo evocador: L'Hostalot. Muñoz Catalá nos señala el lugar y hace especial hincapié en su importancia (12) como yacimiento romano, emplazado dentro del término de Villanueva de Alcolea, junto a la carretera de Castellón a San Mateo.

Normalmente se atribuye a este lugar otra reducción toponímica, lo que no sería óbice para emplazar aquí Lubricatum y buscar otro lugar para Hildum. No obstante, todo está en el aire y sólo una profundización en los topónimos de la donación de los castillos de Mirabet y Zufera, en la cual sigo trabajando, nos podrá dar alguna luz sobre el tema. Quede por el momento la propuesta de identificación entre los tres topónimos: la bajorromana Lubricatum, el altomedieval rahal al-Lobrecatí y la turris de Lupricato. Si se acepta la ecuación, la reducción a lugar o despoblado actual será factible en la medida que se pueda afinar la topografía descrita en el documento o si se encuentra algún otro subsidio que complemente e ilustre lo ya conocido. En ello estoy por el momento y ya habrá ocasión de volver sobre el tema en estas páginas cuando existan suficientes novedades.

\footnotetext{
(11) O.c., nota 4.

(12) A. MUÑOZ CATALA, Algunas observaciones sobre vias romanas de la provincia de Castellón, Archiva de Prehistoria Levantina, Xll, $1972,149 \mathrm{ss}$.
} 